\title{
O CONTRATO INCOMPLETO E A ANÁLISE ECONÔMICA DO DIREITO
}

\section{Paula Greco Bandeira ${ }^{1}$}

\begin{abstract}
Resumo
A análise econômica do direito, embora forneça importante contribuição para as instituições jurídicas, ao inserir a eficiência como objetivo primordial do direito, não atende aos diversos outros valores que devem ser promovidos pelo ordenamento, como a dignidade e a solidariedade social. Assim, os institutos jurídicos, em especial o contrato incompleto examinado neste trabalho, hão de ser compreendidos à luz da perspectiva funcional que atinge os fatos jurídicos.
\end{abstract}

Palavras-chave: análise econômica do direito; contrato incompleto; risco; função; gestão negativa de riscos.

\section{INTRODUÇÃO: O CONTRATO NA ANÁLISE ECONÔMICA DO DIREITO}

A análise econômica do direito preocupa-se, em uma palavra, com eficiência² (FRIEDMAN, 1987, p. 145). Se, por um lado, o ordenamento jurídico volta-se à produção de normas jurídicas válidas, que emanem de autoridade competente, e, por isso mesmo, sejam dotadas de coercibilidade, de modo que a violação da norma enseje o recurso ao Poder Judiciário para garantir o respeito à norma violada e à ordem estabelecida ${ }^{3}$ (BOBBIO,

\footnotetext{
${ }^{1}$ Doutora e Mestre em Direito Civil pela Universidade do Estado do Rio de Janeiro (UERJ).E-mail: pgb@tepedino.adv.br

${ }^{2}$ Embora se mostre controversa, na análise econômica do direito, a persecução da eficiência como único propósito da lei, admite-se majoritariamente a eficiência econômica como importante objetivo das leis ou relevante meio para atingir outros objetivos. Sobre o ponto, assinala David Friedman: "O uso da análise econômica para determinar o quê a lei deveria ser começa com uma simples e controvertida premissa - a de que o único propósito da lei deveria ser promover a eficiência econômica. Existem dois problemas com essa premissa. O primeiro de que isso depende da assunção utilitarista - de que o único bem é a felicidade humana, definida não como o quê as pessoas deveriam querer mas como o quê elas querem. O segundo é que a eficiência econômica fornece, da melhor forma possível, uma medida muito aproximada do que a maior parte de nós entende por 'felicidade humana total', tendo em vista que assume afastado o problema das comparações interpessoais de utilidade a partir do tratamento das pessoas como se todas elas tivessem a mesma utilidade marginal de renda. Uma resposta a essa crítica é que enquanto poucas pessoas acreditam que a eficiência econômica é tudo o que importa, a maior parte das pessoas que entendem o conceito concordaria que a eficiência ou é um importante objetivo ou um importante meio para outros objetivos. Portanto, enquanto maximizar a eficiência econômica pode não ser o único propósito das leis, é um importante objetivo - que a teoria econômica pode, em princípio, nos dizer como alcançar" (FRIEDMAN, 1987, p. 145; tradução livre).

${ }^{3}$ Eis a essência das diversas vertentes do positivismo jurídico, o qual, segundo Norberto Bobbio, considera o direito "como fato e não como valor. (...) Deste comportamento deriva uma particular teoria da validade do direito, dita teoria do formalismo jurídico, na qual a validade do direito se funda em critérios que concernem unicamente à sua estrutura formal (vale dizer, em palavras simples, o seu aspecto exterior), prescindindo do seu conteúdo. (...) considerar o direito como fato leva necessariamente a considerar como direito o que vige como tal numa determinada sociedade, a saber, aquelas normas que são feitas valer por meio da força (...)” (BOBBIO, 2006, pp. 131-132), justamente por emanarem da autoridade competente. Após a Segunda Guerra Mundial, surge a corrente de pensamento do pós-positivismo, que atribui caráter normativo aos valores e princípios constitucionais, que vol. 08, nº. 04, Número Especial. Rio de Janeiro, 2015.pp. 2696-2718 2696
} 
2006, pp. 131-132; SARMENTO, 2010, pp. 233-272; BARROSO, 2009, pp. 229-394) a economia, por sua vez, busca a eficiência em todo o seu funcionamento ${ }^{4}$ (MATTEI et al, 1999, pp. 11-12), valendo-se da segurança jurídica assegurada pelo Direito, e, por vezes, afastando a norma jurídica com o escopo de maximizar as riquezas, de sorte a manusear os institutos jurídicos disponíveis a partir do critério de eficiências (CALABRESI, 1983, p. 89). O Direito, assim, deve atender aos objetivos estabelecidos pela economia ${ }^{6}$ (CALABRESI, 1983, p. 86).

Nesse cenário, o contrato desponta como importante mecanismo para a concretização da eficiência. Com efeito, o direito contratual irá oferecer mecanismos destinados a garantir a higidez dos acordos, minimizando o colapso do processo de troca em que se baseia a economia. Eis a função básica do direito contratual na perpectiva da análise econômica do direito ${ }^{7}$ (POSNER, 1972, p. 42). Por outras palavras, o direito dos contratos tem como função primordial impedir os contratantes de se comportarem oportunisticamente em relação à sua contraparte, com vistas a estimular o tempo ótimo de desenvolvimento da atividade econômica e reduzir os custos de medidas auto protetivas, que seriam adotadas caso o direito contratual não garantisse a exequibilidade dos acordos (POSNER, 2007, p. 94).

O direito contratual, nessa direção, disponibilizaria instrumentos para assegurar o cumprimento dos contratos, como garantias e sanções por inadimplemento, que estimulariam o adimplemento voluntário do negócio, protegendo-se a parte que atua em boa-fé, isto é, na confiança de que as obrigações contratuais serão regulamente cumpridas. Sem aludida proteção, as trocas se revelariam mais arriscadas e, em consequência, mais custosas.

passaram a disciplinar diretamente as relações jurídicas, inclusive as relações privadas. Tal fenômeno adquiriu, no Brasil, contornos específicos, designando-se Neoconstitucionalismo. Sobre o tema, v. SARMENTO, 2010, pp. 233-272; BARROSO, 2009, pp. 229394.

${ }^{4}$ Em interessante passagem metafórica, Ugo Mattei et al. distinguem a economia do direito: "a economia ensina o jurista a acordar do sonho utópico do positivismo legislativo. O jurista está habituado a crer que uma lei seja suficiente para determinar um certo curso dos eventos. O economista, habituado a estudar os mercados (e também os mercados negros), o ensina que tal convicção é resultado de um delírio de onipotência do legislador e que a heterogeneidade dos fins é sempre um engano. (...) a justiça, tradicional estrela polar do jurista, não é vista como um critério idôneo a fundar o discurso científico sobre a organização social. Tal critério se apresenta excessivamente contingente e subjetivo. A análise econômica do direito propõe, a este propósito, substituir o critério da justiça por aquele da eficiência. Uma norma jurídica, uma decisão judicial ou uma doutrina são escolhidas e preferidas não por serem 'mais justas', mas por serem 'mais eficientes'" (MATTEI et al., 1999, pp. 11-12; tradução livre).

${ }^{5}$ A lei deve, com efeito, atender a este objetivo de maximização dos lucros e minimização dos custos propugnado pela economia. Como referido por Guido Calabresi, ao aludir à resposta de Richard Posner às críticas à análise econômica do direito, "qualquer coisa que as pessoas possam dizer, a noção de 'maximização das riquezas' no sentido de minimizar os custos e maximizar os benefícios é em si própria o objetivo de uma sociedade justa ou serve a (indefinidos) objetivos de uma sociedade justa suficientemente favorável a criticar qualquer lei que não atenda a esses requisitos” (CALABRESI, 1983, p. 89; tradução livre).

${ }^{6}$ Neste particular, anota Guido Calabresi: "A análise econômica foi então utilizada para determinar se a específica lei comum ou sub-regras legislativas serviram a alcançar os objetivos admitidos. ( ... ) A nova análise econômica do direito foi um pouco diferente: esta objetiva utilizar ferramentas derivadas da economia para analisar, explicar e criticar as regras legais as quais não eram, em nenhum sentido, intencionalmente, de modo automático, econômicas na origem” (CALABRESI, 1983, p. 86; tradução livre).

${ }^{7} \mathrm{Na}$ síntese de Richard A. Posner: "o direito dos contratos tem como função básica diminuir os colapsos no processo de troca" (POSNER, 1972, p. 42; tradução livre). 
Tal papel se revela sobremaneira importante em relações de execução diferida ou continuada, nas quais muitas contingências podem obstar o processo de troca, que objetiva realocar os recursos para usos mais valiosos ${ }^{8}$ (POSNER, 1972, p. 41). Nesse particular, o direito contratual terá como desafio, para além do oportunismo das partes, a previsibilidade limitada dos contratantes, que não se mostram capazes de prever todas as contingências que podem afetar a execução do contrato de longa duração.

Diga-se, entre parênteses, que os potenciais custos decorrentes de previsibilidade imperfeita podem ser reduzidos por meio de contratos de menor prazo; ou, ainda, mediante a celebração de contrato incompleto, no qual se acordam apenas alguns aspectos da relação, deixando-se os demais elementos pendentes de definição pelas partes em futura negociação ou, em caso de disputa, pela Corte ou árbitro. Nessa última hipótese, as partes escolhem esse particular método econômico de enfrentamento de contingências quando, embora estejam conscientes de que as contingências possam se materializar, estas se afiguram tão improváveis que os custos de redação de contrato completo excedem os benefícios. Assim, torna-se mais barato atribuir à Corte o poder de preencher a lacuna caso a contingência se materialize (POSNER, 2007, p. 96). O juiz, ao fixar o elemento deixado em branco, deverá levar em conta a intenção das partes, precisamente como estas teriam contratado caso a contingência tivesse se materializado à época da negociação. $\mathrm{Na}$ ausência de prova em contrário, há de se considerar a solução mais eficiente como aquela desejada pelas partes para fins de preenchimento da lacuna.

Observe-se que os mecanismos de estímulo ao adimplemento voluntário do negócio, oferecidos pelo direito contratual, não exaurem a sua função de promoção do uso eficiente dos recursos. O direito contratual também se revelará importante, na perspectiva da análise econômica do direito, ao estabelecer, no caso concreto, responsabilidades que tenham por escopo impedir a repetição da mesma conduta culposa em situações futuras. Preocupa-se a economia sobretudo com a repercussão daquela medida adotada in concreto em casos futuros, a qual servirá para desestimular certas condutas e, em consequência, reduzir os custos. Suponha-se que A prometa a B entregar mercadorias no dia vinte. B pensa que será no dia vinte deste mês, mas A refere-se ao dia vinte do mês próximo. Imagine-se que exista um costume nesse mercado de que a data de entrega sem especificação do mês refere-se ao mês corrente, regra essa desconhecida por A por ser novo player nesse mercado. A imposição de responsabilidade a A por não entregar a mercadoria no dia vinte deste mês terá o efeito salutar de estimular aos novos participantes o estudo adequado das regras desse mercado9 (POSNER, 1972, p. 43).

Por outro lado, segundo a economia, a atribuição de culpa a uma das partes pelo inadimplemento do contrato dependerá de se verificar a quem seria menos custoso o cumprimento do dever contratual. Àquele que teria menos custos para adimplir o dever contratual imputa-se a culpa pelo inadimplemento. Cuida-se de

\footnotetext{
${ }^{8}$ Anota Richard A. Posner: "Existem muitas contingências que podem impedir o processo de troca de operar no sentido de realocar os recursos para usos mais valiosos, especialmente quando a troca ocorre durante período de tempo ao invés de simultaneamente ou quando o desempenho de uma ou ambas as partes envolve tarefa complicada" (POSNER, 1972, p. 41; tradução livre).

${ }^{9}$ Eis o exemplo de Richard A. Posner (POSNER, 1972, p. 43).
} 
distribuição de riscos não efetuada expressamente pelo contrato, atribuindo-se, segundo o ponto de vista da eficiência econômica, o risco de inadimplemento à parte que poderia evitá-lo a menor custo. Exemplo típico consiste na alocação de responsabilidade pelo dever de inspecionar a mercadoria e, portanto, de verificar o seu defeito, em contratos de compra e venda. Se, por exemplo, o vendedor de lã entrega ao alfaiate lã defeituosa, cujo defeito era desconhecido do vendedor, e ambas as partes não cumprem o dever de inspecionar a mercadoria, a responsabilidade pelo dever de inspecionar será do alfaiate caso seja mais barato para ele o cumprimento desse dever e, portanto, sua ação de responsabilidade por inadimplemento contratual contra o vendedor será julgada improcedente (POSNER, 1972, p. 44). Em contratos de consumo, do mesmo modo, se o consumidor habitualmente adquire certa mercadoria, de natureza simples, considera-se que os custos para obter a informação quanto ao produto são menores para o consumidor do que para o vendedor, de modo que se imputa ao consumidor a responsabilidade em examinar a coisa e verificar sua qualidade (POSNER, 1972, p. 51).

Como se vê, em todas as hipóteses referidas, a economia indica a solução a partir do critério de eficiência, ao qual, segundo defende a análise econômica do direito, devem se curvar as regras jurídicas.

No que se refere aos contratos de longa duração, que se sujeitam à verificação de superveniências, a eficiência propugnada pela economia objetiva, basicamente, a solução que maximize o saldo à disposição das partes. Tal solução seria eleita pelas partes caso, no momento de estipulação do contrato, conhecessem o fato superveniente que atingiu as suas prestações. Em termos de eficiência, o modo como o saldo é partilhado entre as partes se mostra irrelevante. Ou seja, a eficiência requer a maximização da soma dos ganhos dos contratantes.

Além disso, o critério de eficiência irá determinar se, no decorrer da execução do contrato, a parte deverá adimplir seus deveres contratuais ou se, ao revés, poderá se eximir do cumprimento de suas obrigações. Em determinados casos, o adimplemento não representa a solução eficiente e, por isso, deve ser afastado sob o ponto de vista da análise econômica do direito. Cuida-se das hipóteses em que os ganhos decorrentes da quebra contratual excedem os lucros esperados com a execução do contrato; ou, ainda, superam os lucros esperados pela contraparte com o adimplemento contratual e os danos decorrentes do inadimplemento se limitam à perda do lucro esperado.

Dito diversamente, o custo da execução do contrato corresponde ao lucro da parte infratora com o inadimplemento. Se esse custo é maior do que o seu lucro decorrente do adimplemento, a execução do contrato significará perda para o infrator. Se essa perda é maior do que o ganho da vítima com o adimplemento, inadimplir maximizará os recursos e, por isso mesmo, deve ser incentivado ${ }^{10}$ (WITTMAN, 2006, p. 203). O

\footnotetext{
${ }^{10}$ Como sublinha Donald Wittman, "isso pode parecer imoral, mas economistas acreditam em quebra eficiente. Isto é, economistas não querem que a pessoa cumpra o contrato quando o custo de fazê-lo é maior do que o benefício para a outra parte" (WITTMAN, 2006, p. 203; tradução livre).
} 
inadimplemento, em síntese, é cometido para evitar uma perda maior ${ }^{11}$ (POSNER, 1972, p. 57). A economia estimula, nesses casos, o inadimplemento, a que se denomina quebra eficiente (efficient breach).

A título exemplificativo, em contratos de fornecimento, se, após a conclusão do contrato, no curso de sua execução, o fornecedor descobre que os custos de produção aumentaram consideravelmente, de modo a superar os danos que decorreriam de seu inadimplemento, o inadimplemento será considerado a solução eficiente.

O adimplemento consistirá em solução eficiente apenas se os custos de execução da prestação se revelarem inferiores aos denominados danos de expectativa, ou seja, ao somatório dos danos emergentes e lucros cessantes que adviriam à contraparte na hipótese de inadimplemento. Em outros termos, a solução eficiente preconiza a execução se e apenas se os benefícios dela decorrentes superem os custos.

Caso os custos de execução se afigurem superiores aos danos de expectativa, a solução eficiente consistirá em conceder à parte a possibilidade de não adimplir a prestação e ressarcir a contraparte do inadimplemento. $\mathrm{O}$ ressarcimento eficiente corresponderá àquele que atribui à parte inadimplente os custos do inadimplemento, precisamente os danos de expectativa.

Convém sublinhar que, mesmo que o sistema jurídico determine a execução específica da prestação na hipótese de inadimplemento, tal solução, de acordo com a análise econômica do direito, deve ser afastada se se revelar ineficiente, ou seja, se os custos da execução específica da prestação forem superiores à soma dos danos emergentes e lucros cessantes sofridos pela parte em razão do inadimplemento (rectius, danos de expectativa).

Ao propósito, Posner sustenta que, em muitos casos, se afigura antieconômico determinar a execução específica do contrato inadimplido, pois resultaria em perda de recursos. Vale dizer, a troca, se realizada após o descumprimento contratual, não acarretaria aumento de valor dos recursos empregados, como pretende a economia. A solução, desse modo, seria o inadimplemento acompanhado do ressarcimento dos danos sofridos pela vítima por força da violação contratual (POSNER, 1972, pp. 55-56).

Ao lado do papel do direito contratual de incentivar condutas eficientes em situações de troca, pode-se indicar duas outras funções econômicas do direito dos contratos. A primeira consiste em reduzir a complexidade e, portanto, os custos de transação, mediante o fornecimento de conjunto de cláusulas que devem ser negociadas expressamente pelas partes na ausência de previsão legal específica.

E, em segundo lugar, o direito contratual serviria a fornecer informação quanto a contingências que poderiam atingir a relação, de modo a auxiliar as partes no planejamento da troca (POSNER, 1972, p. 44). Nesse particular, nenhum contrato prevê todas as possíveis contingências, tendo em vista a racionalidade limitada dos

\footnotetext{
${ }^{11}$ Assinala, ao propósito, Posner: "Isso (a quebra) ocorreu apenas para evitar perda maior. A parte infratora teria ficado mais feliz se não tivesse tido ocasião de inadimplir. Mas, em alguns casos, a parte ficará tentada a violar o contrato simplesmente porque o seu lucro com a quebra excederia sua expectativa de lucro com o cumprimento do contrato. Se o seu lucro decorrente da violação excederia o lucro esperado para a outra parte com o cumprimento do contrato, e se os danos estão limitados à perda do lucro esperado, então haverá um incentivo a cometer a violação" (POSNER, 1972, p. 57; tradução livre).
} 
contratantes e os custos de transação que, especialmente em contratos de longa duração, se afigurariam extremamente elevados.

Diante disso, o direito contratual oferece múltiplos e variados arranjos negociais ${ }^{12}$ por meio dos quais se efetuará a troca, com vistas a reduzir os custos de transação e superar a previsibilidade limitada das partes quanto à materialização das contingências. A variedade de contratos, de fato, se justifica pelos diferentes custos de transação a eles associados (CHEUNG, 2004, p. 323-325). De outra parte, diversos arranjos contratuais importarão diferente distribuição de renda entre os contratantes. Sob a premissa de aversão ao risco, o indivíduo irá evitar o risco se o custo de o fazer for inferior ao ganho com o risco evitado. O sujeito poderá se esquivar do risco ao buscar informações sobre o futuro, escolher opções de menor risco ao investir ou escolher contratos nos quais o risco esteja diluído entre outros indivíduos, como o contrato de seguro.

Pode-se afirmar, nessa direção, que o direito contratual se destina a minimizar os custos:

1. Das partes na elaboração dos contratos;

2. Dos juízes ao interferir nos negócios integrando suas lacunas; e

3. De comportamentos ineficientes decorrentes de contratos mal escritos ou lacunosos.

Em suma, o direito contratual orienta as partes a adotar o comportamento eficiente nas circunstâncias do caso concreto (WITTMAN, 2006, p. 194), reduzindo os custos de transação.

Os custos de transação consistem nos custos de se alcançar e executar um acordo ou troca de direitos ${ }^{13}$ (CHEUNG, 1987, pp. 56-57). Pode-se indicar como fatores que favorecem o aumento dos custos de transação:

1. Os custos decorrentes de monopólio bilateral ${ }^{14}$ com muitos participantes de ambos os lados, cenário em que não há competição, de modo a incitar os contratantes a barganharem na busca do melhor negócio possível; e

2. Os custos de monitorar e executar o contrato, assim como o custo incorrido quando uma ou ambas as partes recusam o acordo (WITTMAN, 2006, p. 34)

Ao propósito dos custos de transação, Ronald Coase, responsável por cunhar conceitos fundamentais na análise econômica do direito, elaborou o teorema, conhecido por Teorema de Coase, segundo o qual se os custos

\footnotetext{
${ }^{12}$ Note-se que a existência do risco natural, compreendido como a contribuição da natureza para a variação do valor do produto, concorre para essa variedade de contratos.

${ }^{13} \mathrm{Na}$ definição de Steven N.S. Cheung, "custos de transação podem ser vistos como espectro de custos institucionais, incluindo aqueles de informação, negociação, de elaboração e execução de contratos, de delimitação e policiamento de direitos de propriedade intelectual, monitoramento da execução e de mudanças de arranjos institucionais. Em síntese, eles compreendem todos aqueles custos não diretamente incorridos no processo físico de produção. ( ... ) Cada tipo de contrato implica diferentes custos de supervisão, de medida, de negociação e de forma da organização econômica, juntamente com a função da mão visível, mudanças que sempre ocorrem quando um arranjo contratual diferente é escolhido" (CHEUNG, 1987, pp. 56-57; tradução livre). ${ }^{14}$ Monopólio bilateral se configura na hipótese em que cada parte detém aquilo que a outra parte deseja e não existem condições comerciais que estabeleçam qual deve ser a taxa de troca. Ou seja, não há substituto do produto no mercado, não existindo competição.
} 
de transação são iguais a zero e se negócios mutuamente benéficos são levados a cabo quando os custos de transação se afiguram baixos, então, seja qual for a atribuição inicial de direitos:

1. O resultado será eficiente; e

2. O resultado será o mesmo quando mudanças na distribuição de riquezas não afetem padrões de consumo $^{15}$ (COASE, 1988, p. 157 e ss.; WITTMAN, 2006, p. 34).

A troca somente se operará no mercado se os custos de transação forem inferiores ao benefício líquido decorrente do contrato (PARISI, 1999, p. 23).

Em outras palavras, quando os custos de transação são iguais a zero, a alocação final será a mesma, independentemente da atribuição inicial de direitos. Ou seja, na ausência de custos de transação, não importa a titularidade inicial dos direitos, já que os indivíduos irão contratar de qualquer maneira, com vistas à alocação ótima dos recursos. O mercado determina a troca, pouco importando a titularidade dos direitos. A alocação final, assim, maximiza as riquezas, vez que o bem é atribuído à pessoa que pagaria o maior valor por ele. Em singelo exemplo, se eu possuo um bilhete de boxe na primeira fila, mas eu não gosto do esporte, tenho a seguinte alternativa:

1. Posso vender à Tício, que é fã de boxe e me pagará o maior valor possível;

2. Posso doar para Tício; ou

3. Doar para Mévio.

Em todas as hipóteses, qualquer que seja a atribuição inicial de direitos, Tício ficará com o bilhete (idêntica alocação final), pois mesmo na opção (3) Mévio provavelmente venderá o bilhete para Tício, disposto a pagar qualquer valor pelo ingresso (maximização das riquezas) (WITTMAN, 2006, p. 38).

A lógica do Teorema de Coase consiste no fato de que, se não há custos de transação, parte-se da premissa de que todos os ganhos mutuamente benéficos serão obtidos e o resultado será a melhoria de Pareto ${ }^{16}$ (WITTMAN, 2006, p. 42; PARISI, 1999, p. 13). Neste contexto, a escolha do regime legal, com a atribuição de responsabilidades, afigura-se irrelevante, pois a atribuição inicial de direitos não tem qualquer efeito na alocação final.

Ao revés, quando os custos de transação se revelam muito elevados, a escolha do regime legal (ex. qual parte é responsável pelo dano) mostra-se sobremaneira importante, tendo em vista que as partes não serão

\footnotetext{
${ }^{15}$ A discussão acerca do Teorema de Coase revela-se extensa na literatura da economia. V. sobre o ponto, COASE, 1988, p. 157 e ss. O autor afirma categoricamente que "quando existem custos de transação zero, negociações levarão a um acordo que maximiza a riqueza” (Ibidem, p. 159; tradução livre). V. tb. WITTMAN, 2006, p. 34.

${ }^{16}$ Ao propósito, Francesco Parisi afirma que Coase parte da premissa de que, no livre mercado, os bens se movem em direção à alocação ótima de acordo com o critério da eficiência de Pareto (PARISI, 1999, p. 13).
} 
capazes de negociar acerca da atribuição inicial de direitos ${ }^{17}$ (MÜLLER e TIETZEL, 1999, p. 41). A alocação inicial de direitos será provavelmente idêntica à alocação final. A atribuição de responsabilidades será levada a cabo a partir de análise de custo e benefício, que determinará o resultado ótimo e as regras que incentivarão a obtenção desse resultado ${ }^{18}$ (FRIEDMAN, 1987, p. 145).

A análise de custo e benefício parte do pressuposto de que agente e vítima poderiam ter evitado o dano. A questão reside em saber qual pessoa poderia ter evitado o dano no menor custo e se esse custo de prevenção é menor do que o dano verificado (WITTMAN, 2006, p. 56 e ss). Essa pessoa, que teria capacidade de impedir o dano no menor custo e em valor inferior aos danos causados e não o fez, há de ser responsabilizada. Eis a solução eficiente, que deverá ser indicada pela lei.

Diante do exposto, pode-se afirmar, à luz da análise econômica do direito, que o direito contratual desempenha diversas funções econômicas, notadamente a de:

1. Estimular o adimplemento voluntário do negócio, com a garantia de sua exequibilidade mediante o recurso ao Poder Judiciário;

2. Impedir o oportunismo das partes;

3. Contornar a previsibilidade limitada dos contratantes, por meio de diferentes técnicas contratuais;

4. Definir as responsabilidades mediante o critério de eficiência;

5. Determinar a conveniência ou inadequação do cumprimento dos deveres contratuais com base na eficiência; e

6. Reduzir os custos de transação ${ }^{19}$ (POSNER, 2007, p. 99).

\footnotetext{
${ }^{17}$ Assinalam Christian Müller e Manfred Tietzel: "Com os custos de transação sendo positivos, os direitos de propriedade nunca serão totalmente definidos, tendo em conta que os indivíduos terão que suportar custos com vistas a estabelecer direitos exclusivos e a explorar o completo potencial de um recurso formalmente titularizado. Enquanto a definição dos direitos de propriedade for cara, o grau de delimitação dos direitos irá depender de cálculos individuais de custo-benefício das partes afetadas" (MÜLLER e TIETZEL, 1999, p. 41; tradução livre).

${ }^{18}$ Anota David Friedman: "Liberdade de contratar não tem utilidade onde não há acordo voluntário entre as partes. A lei deve, de alguma maneira, especificar quem é responsável e sob quais condições pelo custo de acidentes, e qual punição deve ser adotada para crimes. Uma abordagem tradicional para o problema é a 'Fórmula Hand', segundo a qual alguém é julgado negligente e, portanto, responsável legalmente por um acidente, apenas se poderia tê-lo evitado com precauções que teriam custado menos do que o custo esperado (probabilidade multiplicada por danos) do acidente. Isto parece se encaixar cuidadosamente na análise econômica do direito, uma vez que pune alguém somente se ele tiver agido de forma ineficiente ao não tomar uma precaução de custo justificado" (FRIEDMAN, 1987, p. 145; tradução livre).

${ }^{19}$ Na síntese de Posner: "( ... ) o direito contractual tem cinco funções econômicas distintas: (1) prevenir o oportunismo, (2) inserir termos eficientes quer sob atacado, quer em base de varejo (preenchimento de lacuna versus interpretação ad hoc), (3) punir erros evitáveis no processo de contratação, (4) alocar risco para quem suporta riscos superiores, e (5) reduzir os custos de solução de disputas contratuais" (POSNER, 2007, p. 99; tradução livre).
} 


\section{O CONTRATO INCOMPLETO SOB A PERSPECTIVA DA ANÁLISE ECONÔMICA DO DIREITO}

A solução eficiente poderá ser ajustada pelas partes no momento da estipulação do contrato, a partir da celebração do denominado contrato incompleto. Ou seja, as partes preveem negócio de longa duração lacunoso, sem disciplinar todas as possíveis superveniências que poderão atingi-lo, como forma de diminuir os custos de transação e obter resultado mais eficiente.

Em outras palavras, os contratantes racionalmente optam por não regulamentar ex ante ${ }^{20}$ (STEIGER, 1987, p. 200) todas as contingências (isto é, riscos), com o escopo de reduzir os custos de transação, embora, normalmente, indiquem o procedimento a ser adotado na hipótese de ocorrer determinada superveniência ex post, permitindo, assim, extrair do contrato a máxima eficiência. Tal se verifica sobretudo em projetos de investimentos complexos, que impossibilitam aos contratantes definir antecipadamente todos os elementos da relação jurídica, seja pela racionalidade limitada das partes em prever todas as contingências que possam afetar o contrato, seja pelo elevado custo de transação incorrido na elaboração de contrato completo $^{21}$ (BELLANTUONO, 2001, pp. 261-262).

A racionalidade limitada dos contratantes, com efeito, relaciona-se à impossibilidade de as partes anteverem todas as contingências que possam se verificar supervenientemente à celebração do contrato e, em consequência, de especificarem todas as soluções concebíveis referentes aos possíveis "estados do mundo". Por "estado do mundo", compreende-se o conjunto de eventos exógenos, ou seja, fora do controle das partes, capazes de influenciar os incentivos dos contratantes e, em definitivo, o resultado e a execução contratual. Referido "estado do mundo" caracteriza-se pela incerteza quanto à sua dinâmica e ao seu valor ${ }^{22}$ (CLERICO, 2005, p. 593). Em casos de assimetria informativa ${ }^{23}$ (MATTEI et al, 1999, p. 64), todavia, uma parte poderá dispor de maiores informações do que a outra relativamente ao "estado do mundo".

Giuseppe Bellantuono recorda, ao propósito, possíveis contingências, não presumidas pelas partes, que poderiam afetar o negócio, a justificar a escolha em celebrar contrato incompleto:

\footnotetext{
${ }^{20}$ A terminologia ex ante e ex post foi introduzida na teoria macroeconômica e se origina do reconhecimento da diferença entre mudanças previsíveis e imprevisíveis, decorrendo apenas desta última ganhos e perdas. A análise econômica pode se dividir em (i) análise ex ante, que explica como as expectativas determinam uma magnitude econômica; e (ii) análise ex ante/ex post, esclarecendo a possível divergência entre o valor esperado e o realizado dessa variável. V., sobre o ponto, STEIGER, 1987, p. 200.

${ }^{21}$ Acerca dos obstáculos para a redação de contrato completo, anota Giuseppe Bellantuono: “(...) o principal obstáculo para a redação de um contrato completo é a impossibilidade de prever todos os estados do mundo futuros. Também os contratantes mais sofisticados circunscrevem o seu acordo a uma pequena porção das circunstâncias potencialmente relevantes para a execução do contrato. A incompletude é inevitavelmente associada à racionalidade limitada, que amplia os custos dos processos decisionais e impede de dirigir-se além da valoração de um restrito número de informações” (BELLANTUONO, 2001, pp. 261-262; tradução livre).

${ }^{22}$ Sobre o conceito de "estado do mundo", v. CLERICO, 2005, p. 593.

${ }^{23}$ Considera-se assimetria informativa "caso de fortes desequilíbrios, tão fortes que uma parte da troca tem uma vantagem significativamente injusta em comparação com a outra” (MATTEI et al, 1999, p. 64; tradução livre).
} 
As variações dos custos de produção, as condições da demanda ou as inovações tecnológicas podem influenciar a execução do programa contratual. Vincular as obrigações de cada contratante a qualquer um desses eventos poderia garantir o alinhamento do contrato às mudanças do ambiente econômico (BELLANTUONO, 2001, p.261).

$\mathrm{O}$ contrato incompleto, nessa perspectiva, não regulamentaria os efeitos que possíveis contingências, caso materializadas, poderiam gerar imediatamente no negócio, permitindo a abertura do regulamento contratual, que, mercê das mudanças do ambiente econômico, se submeteria à posterior definição dos elementos faltantes ${ }^{24}$ (CLERICO, 2005, p. 593).

A incompletude do contrato garantiria, portanto, maior flexibilidade contratual, proporcionando aos contratantes maior maleabilidade para se adaptar às mudanças dos "estados do mundo". Tal flexibilidade seria desejável em contextos de incerteza, no qual as partes definiriam apenas algumas variáveis, especialmente aquelas em relação às quais subsistisse interesse e objetivo absolutamente opostos, como, por exemplo, o preço (CLERICO, 2005, p. 595).

Imagine-se a hipótese em que certo empreendedor precise levantar fundos para financiar um projeto de investimento. Decisões futuras acerca desse projeto devem ser tomadas, mas não podem ser perfeitamente determinadas no contrato inicial. Além disso, empreendedor e investidor podem possuir objetivos conflitantes relativamente ao desenvolvimento do projeto ${ }^{25}$ (AGHION e BOLTON, 2008, pp. 410-411). Nesse caso, o contrato incompleto, ao definir apenas determinados aspectos da relação, permite a deflagração do projeto, postergando para momento futuro a definição dos elementos faltantes, de modo a reduzir os custos de transação.

Como já referido, para além de contornar o problema da racionalidade limitada dos contratantes, o contrato incompleto reduz os custos de transação. Entende-se por custos de transação notadamente:

1. O custo de cada parte de antecipar várias eventualidades que podem ocorrer no contrato de longa duração;

2. O custo de decidir e atingir acordo sobre como lidar com essas eventualidades;

3. O custo de redigir um contrato de modo claro e sem ambiguidades, a fim de torná-lo exequível; e

4. Os custos legais de execução (HART, 1987, p. 753).

Desse modo, sempre que o custo efetivo da negociação de cláusula específica - que distribua entre as partes o risco de determinado evento ocorrer - se revelar superior aos custos esperados de intervenção necessária ao preenchimento da lacuna, mostra-se preferível deixar a lacuna no contrato ${ }^{26}$ (MATTEI et al, 1999, p. 224). Cuida-se de lacuna voluntária, desejada pelos contratantes, tendo em conta que os riscos remotos de determinado

\footnotetext{
${ }^{24} \mathrm{O}$ contrato incompleto se contrapõe, portanto, ao contrato completo, celebrado em condições ideais que caracterizam o mercado de concorrência pura e perfeita. No contrato completo, as partes concordam sobre a solução e o resultado dos infinitos possíveis "estados do mundo". V., nesse sentido, CLERICO, 2005, p. 593.

${ }^{25}$ Eis o exemplo de AGHION e BOLTON, 2008, pp. 410-411.

${ }^{26}$ Os custos esperados de preenchimento da lacuna são obtidos a partir da multiplicação da probabilidade de o evento ocorrer (materialização da perda) pelo custo de alocação dessa perda.
} 
evento se implementar não justificam os custos de negociação e redação de cláusula que aloque esses riscos entre as partes. Considera-se, portanto, eficiente o contrato que apresenta lacunas relativas aos riscos remotos.

Outras razões justificam o contrato incompleto para a análise econômica do direito. Pode-se indicar, ao lado da redução dos custos de transação:

1. A vagueza da linguagem, que não é suficientemente rica para descrever todos os possíveis acontecimentos;

2. O esquecimento, pois as partes, involuntariamente, omitem eventualidades importantes no momento da celebração do contrato; e

3. A assimetria de informações (FRANZONI, 2003, p. 128).

Afirma-se, assim, que as partes preferem não incluir no contrato várias contingências do que prever inúmeras eventualidades improváveis, sob o ponto de vista de que é melhor "esperar para ver o que acontece" (HART, 1987, p. 753). Verificada a superveniência, as partes objetivarão numerosas vezes renegociar o contrato, que apresentará, frequentemente, de modo inevitável, cláusulas vagas ou ambíguas.

Ao não prever as obrigações das partes de modo exaustivo, o contrato incompleto apresentará lacunas, para cujo preenchimento se afigurarão relevantes o costume e a reputação das partes no mercado (HART, 1987, p. 758). Além disso, torna-se importante a alocação dos direitos de decisão ou direitos de controle, isto é, determinar a quem compete tomar a decisão caso se verifique a superveniência. No caso em que seja dispendioso regular precisamente como usar determinado ativo em diversos cenários, mostra-se mais eficiente atribuir a uma das partes o controle do ativo, permitindo-lhe fazer o que julgar conveniente, sujeito a limitações (HART, 1987, p. 758).

Do ponto de vista da análise econômica do direito, portanto, o contrato incompleto não apresenta lacunas em sentido técnico, mas limita-se a não prever as obrigações e direitos contratuais específicos para todas as possíveis circunstâncias que possam se verificar ("estados do mundo"). Vale dizer: configura-se lacuna, para a análise econômica do direito, quando o contrato é silente acerca de determinado risco, que incide sobre as obrigações assumidas pelas partes ${ }^{27}$ (MATTEI et al, 1999, p. 223). Diversamente da lacuna em sentido jurídico, que se configura pela ausência de especificação de determinado elemento da relação contratual, que é deixado em branco, a incompletude em sentido econômico prescinde da verificação de lacuna em sentido técnico, considerando relevante o descolamento entre o negócio celebrado pelas partes e as circunstâncias efetivamente verificadas (BELLANTUONO, 2001, p. 262). A título exemplificativo, determinado contrato de fornecimento será considerado incompleto caso não preveja os direitos e obrigações das partes na hipótese de aumento

\footnotetext{
${ }^{27} \mathrm{Na}$ definição de Ugo Mattei, para a análise econômica do direito, "as lacunas são eventos, não regulados explicitamente no contrato, que incidem sobre as obrigações assumidas pelas partes” (MATTEI et al, 1999, p. 223; tradução livre). 
excessivo dos custos de produção (FRANZONI, 2003, p. 127). Nessa perspectiva, os contratos, em sua maioria, afiguram-se incompletos.

Vale notar que o estudo do contrato incompleto, mesmo sob o ponto de vista da economia, se apresenta em estágio inicial, embora o instituto tenha significativa relevância prática ${ }^{28}$ (HART, 1987, p. 758).

\section{O CONTRATO INCOMPLETO SOB A PERSPECTIVA FUNCIONAL: CRÍTICA A ANÁLISE ECONÔMICA DO DIREITO}

A análise econômica do direito, como se depreende do exposto, inaugura novo sistema de responsabilidades, na esfera contratual e extracontratual, pautado pelo critério de eficiência. Como visto, no âmbito contratual, a responsabilidade é atribuída ao contratante a quem se revela menos custoso o cumprimento de determinado dever. Por outro lado, caso o adimplemento do dever contratual deflagre custos maiores do que os prejuízos decorrentes da violação do contrato, estimula-se o inadimplemento (quebra eficiente), acompanhado do ressarcimento dos danos causados à vítima, por representar a solução mais eficiente, que maximiza as riquezas. De igual modo, no âmbito extracontratual, a imputação da responsabilidade baseia-se na análise de custo e benefício, reputando-se como responsável aquele que poderia evitar o dano no menor custo e em valor inferior aos danos verificados.

Entretanto, o critério de eficiência que orienta o arcabouço teórico da análise econômica do direito, posto que relevante em determinadas hipóteses, não consiste no único valor do ordenamento jurídico brasileiro, como antes assinalado. Embora o legislador e o intérprete, em certas situações, recorram ao critério de eficiência, outros valores e princípios constitucionais, introduzidos ao sistema aberto e mutáveis a cada momento histórico, hão de ser promovidos pela iniciativa privada ${ }^{29}$ (FACHIN, 2015, p. 69).

A análise econômica do direito, portanto, a despeito de constituir relevante método de análise empregado pelo legislador ou intérprete em determinadas situações, não exaure a complexidade de valores integrantes do sistema jurídico, não tendo, desse modo, na legalidade constitucional, o condão de ditar os critérios interpretativos para a solução dos casos concretos. Em um ordenamento solidarista e personalista, diversos outros valores e princípios, de estatura constitucional, que não se confundem com a eficiência, incidirão na solução dos

\footnotetext{
${ }^{28}$ Esta foi a constatação de HART, 1987, p. 758.

${ }^{29}$ Especialmente em relação ao direito contratual, assinala com acerto Luiz Edson Fachin que "com a evolução da ordem jurídica e mudança na relação entre os contratantes, surgem limites e os contratantes já não podem definir sozinhos o conteúdo do contrato, que pode sofrer intervenção do legislador e submeter-se à revisão pelo Judiciário, além da força construtiva dos fatos sociais e também especialmente a eficácia vinculante dos comportamentos concludentes na execução contratual, não raro apta a alterar o programa contratual originário. A autonomia privada é relativizada para que haja uma justiça substancial, com a confiança assumindo papel de destaque na relação contratual. Com essa formulação renovada, a teoria dos contratos se direciona para o equilíbrio entre as partes na relação contratual, entendida como processo, e vedadas são não somente cláusulas abusivas diante da adoção de novos paradigmas interpretativos, como também (e especialmente) é obstado um programa contratual que, mesmo na licitude, seja o sinal de uma extorsão do conteúdo econômico de uma parte em detrimento da outra" (FACHIN, 2015, p. 69).
} vol. 08, nº. 04, Número Especial. Rio de Janeiro, 2015.pp. 2696-2718 
conflitos de interesses, o qual será dirimido a partir da técnica da ponderação. Além disso, a perspectiva funcional dos fatos jurídicos, adotada pela metodologia de direito civil-constitucional, determinará a preponderância das situações jurídicas existenciais, mediante a funcionalização das situações jurídicas patrimoniais às existenciais, que desfrutarão, por isso mesmo, de tutela jurídica diferenciada.

Nessa direção, o magistrado, ao julgar o caso que lhe é submetido, há de fazê-lo com base no inteiro ordenamento jurídico: unitário, sistemático e complexo. Recorrerá, assim, aos diversos valores e princípios, "reconduzindo-os da fragmentação da casuística à unidade axiológica indispensável à compreensão do ordenamento como sistema" (TEPEDINO, 2014, p. 80). Como advertido por Gustavo Tepedino, no âmbito do sistema aberto, em que convive harmoniosamente uma miríade de valores e princípios, por vezes antagônicas:

Cada regra deve ser interpretada e aplicada em conjunto com a totalidade do ordenamento, refletindo a integralidade das normas em vigor. A norma do caso concreto é definida pelas circunstâncias fáticas nas quais incide, sendo extraída do complexo de textos normativos em que se constitui o ordenamento. $\mathrm{O}$ objeto da interpretação são as disposições infraconstitucionais integradas visceralmente às normas constitucionais, sendo certo que cada decisão abrange a totalidade do ordenamento, complexo e unitário. Cada decisão judicial, nessa perspectiva, é um ordenamento singular extraído da mesma tábua axiológica (TEPEDINO, 2014: pp. 82-83).

Ao propósito, sublinhe-se que a autonomia privada encontrará maior capacidade de expansão no âmbito das situações patrimoniais, em que se verifique simetria de informações, tendo por fundamento o valor social da livre iniciativa (arts. 1º, IV; 170, caput, C.R.), a prevalecer a alocação de riscos estabelecida no contrato, que deverá ser privilegiada pelo intérprete. Em contrapartida, a autonomia privada sofrerá maior controle de atuação nas situações jurídicas existenciais ou nas situações patrimoniais em que uma das partes contratantes se apresente como parte vulnerável, nas quais prevalece a dignidade da pessoa humana (art. 1º, III, C.R.) como fundamento do ato de autonomia, determinando maior intervenção do legislador e do magistrado na defesa de valores fundamentais, de modo a mitigar a atuação dos particulares na distribuição de riscos. Como ensina Pietro Perlingieri a respeito da diversa valoração do ato de autonomia na hierarquia de valores do sistema, de acordo com o seu distinto fundamento:

A constatação de diverso fundamento (constitucional ou comunitário) da autonomia negocial é da máxima importância, ainda que não seja reconhecida adequadamente pela doutrina em seu significado pleno: a um fundamento diverso corresponde uma colocação diferente na hierarquia de valores. Quando a autonomia (o poder de pôr regras) atinge fortemente o valor da pessoa, a consideração do ordenamento não pode ser abstrata, não se pode formalisticamente igualar a manifestação de liberdade que toca profundamente a identidade do indivíduo e a liberdade de perseguir o maior lucro possível: a evidente diferença entre a venda de mercadorias seja ou não especulação profissional - e o consentimento a um transplante corresponde a uma diversidade de valoração no interior da hierarquia dos valores postos pela Constituição, onde a prevalência do valor da pessoa impõe a interpretação de cada ato ou atividade dos sujeitos à luz desse princípio fundamental. O fundamento dos vol. 08, nº. 04, Número Especial. Rio de Janeiro, 2015.pp. 2696-2718 
atos de autonomia, portanto, não deve ser atribuído unicamente à liberdade de iniciativa econômica garantida pelo art. 41 Const., mas deve ser relacionado diretamente ao art. 2 quando a negociação concernir a situações jurídicas não patrimoniais (PERLINGIERI, 2008, pp. 348-349).

A corroborar a proteção de outros valores diversos da eficiência, o sistema jurídico brasileiro, na esteira dos ordenamentos de família romano-germânica, afastando-se do critério de eficiência defendido pela análise econômica do direito, de um lado, prestigia o sistema de responsabilidades definido pelos contratantes, no livre exercício de sua autonomia privada; e, de outro lado, preocupa-se com a reparação integral de todos os danos sofridos pela vítima (MORAES, 2010, pp. 339-340), em proteção ao princípio da dignidade da pessoa humana (art. 10, III, C.R.). Por tais razões, o intérprete, na definição das responsabilidades, deverá se pautar na complexidade de valores do ordenamento jurídico, não se restringindo ao exame dos custos do inadimplemento ou da evitação do dano, isto é, a critérios econômicos.

Nessa direção, no âmbito contratual, em situações patrimoniais em que haja simetria de informações, há de se respeitar a alocação de riscos estabelecida pelas partes no momento da contratação, vez que a autonomia privada já define, no instrumento contratual, a qual parte incumbe a satisfação de determinado dever, que há de ser regularmente executado, sob pena de responsabilização.

Vige, no direito contratual brasileiro, o clássico princípio do pacta sunt servanda, segundo o qual os deveres contratuais legitimamente pactuados devem ser cumpridos, adquirindo força de lei entre as partes. Nessa medida, se o contrato distribuiu os riscos e delimitou os deveres das partes, estes hão de ser cumpridos pelos seus respectivos titulares. Caso contrário, a parte inadimplente se sujeita às responsabilidades contratuais. Não há, no direito brasileiro, o princípio que se pudesse denominar de proteção ao bom negócio ou ao negócio lucrativo. Contratar é essencialmente se arriscar. Todo contrato se caracteriza pelo risco, ao qual se mostra ínsita a ideia de perda, independentemente da apuração dos lucros e da maximização das riquezas. Do ponto de vista jurídico, portanto, a distribuição dos riscos efetuada pela autonomia privada deve ser respeitada e o contrato há de ser executado nos termos pactuados.

Desse modo, a responsabilidade da parte decorre da violação do dever pactuado no contrato, segundo a alocação dos riscos, não podendo sua imputação se pautar exclusivamente pelo critério da eficiência, em respeito ao exercício da autonomia privada nas situações patrimoniais.

A ideia de quebra eficiente, caso adotada tout court, estimularia a violação contratual sob o manto da eficiência, o que, a um só tempo:

1. Representaria o desmoronamento do sistema contratual brasileiro, que se pauta na obrigatoriedade dos pactos; 
2. Ruiria com a tão festejada regra da execução específica vigente no direito das obrigações e que promove a satisfação do interesse útil do credor; e

3. Abalaria a segurança jurídica, desestimulando novos negócios.

No momento da contratação, as partes, ao fixarem os deveres contratuais, estabelecem a alocação de riscos desejada, a qual fundamenta a equação econômica do contrato e o equilíbrio entre as prestações (rectius, sinalagma). A alteração dos termos contratados se justifica apenas em hipóteses excepcionais, nas quais se configure a onerosidade excessiva, com os pressupostos rigorosamente indicados nos arts. 478 e ss. do Código Civil, a autorizar a intervenção no contrato e a alteração de suas bases para o restabelecimento do equilíbrio inicial ${ }^{30}$. Deste modo, a maximização dos lucros perseguida pelo critério de eficiência da análise econômica do direito não tem o condão de autorizar o descumprimento de contratos legitimamente negociados pela autonomia privada. Apenas se configurada a teoria da imprevisão ou em outros casos excepcionais previstos pelo legislador, admite-se a alteração do pactuado, mediante revisão, ou a extinção do contrato.

Em definitivo, afora a hipótese de onerosidade excessiva, que flexibiliza o princípio da obrigatoriedade dos pactos, autorizando a revisão ou extinção do negócio e servindo de fundamento para eventual descumprimento do contratante e outros casos excepcionais disciplinados em lei, não há, no direito brasileiro, outra justificativa apta a afastar a alocação de riscos estabelecida entre as partes, em situações patrimoniais com simetria de informações entre os contratantes. $\mathrm{O}$ critério de eficiência, dessa feita, não pode determinar o cumprimento ou descumprimento do dever contratual em dissonância com o sistema de distribuição de riscos definido legitimamente pela autonomia privada.

A quebra eficiente colide, ainda, com a regra do direito obrigacional brasileiro que autoriza ao credor, na hipótese de descumprimento contratual, sempre que possível, requerer a execução específica da obrigação inadimplida (art. 475 $5^{31}$, Código Civil; arts. 461 32 e 461- $\mathrm{A}^{33}$, Código de Processo Civil). Em reconhecida e conclamada evolução, o direito obrigacional hodierno alterou o sistema anterior, o qual oferecia ao credor, em regra, diante do inadimplemento do devedor, a possibilidade de pleitear as perdas e danos sofridos ${ }^{34}$ (SANTOS,

\footnotetext{
${ }^{30}$ Há, ainda, outras hipóteses excepcionais de alteração do pactuado previstas pelo legislador, como a lesão (art. 157, Código Civil), vício do consentimento que macula a vontade originária, autorizando o juiz a rever o negócio ou a anulá-lo, caso a parte favorecida não concorde com a redução do proveito.

31 "Art. 475. A parte lesada pelo inadimplemento pode pedir a resolução do contrato, se não preferir exigir-lhe o cumprimento, cabendo, em qualquer dos casos, indenização por perdas e danos”.

${ }^{32}$ Tal dispositivo corresponde ao art. 497, CPC/2015.

${ }^{33}$ Tal dispositivo corresponde ao art. 498, CPC/2015.

${ }^{34}$ A regra das perdas e danos encontrava-se disciplinada no art. 1.056 do Código Civil de 1916. Como constatou J. M. Carvalho Santos no regime anterior, "em certos casos, a indenização das perdas e danos é mesmo a única solução possível na inexecução das obrigações, o que acontece, por exemplo, nas obrigações de não fazer, e a solução mais frequente na das obrigações de fazer” (SANTOS, 1964, p. 176).
} 
1964, p. 176). Não se disponibilizavam ao credor, assim, na esteira do sistema jurídico francês ${ }^{35}$, instrumentos que lhe possibilitassem exigir o cumprimento específico da prestação inadimplida. Atualmente, sob o influxo do princípio da conservação dos contratos ${ }^{36}$ (AZEVEDO, 2008, pp. 66-67; AMARAL, 2003, p. 544), e, em atendimento ao critério do interesse útil do credor, sempre que o credor vislumbre utilidade na manutenção do vínculo contratual, poderá requerer a execução específica da obrigação inadimplida, oferecendo o direito processual contemporâneo diversos mecanismos que assegurem o resultado almejado. Como observado com perspicácia por Cândido Dinamarco: "os sistemas processuais modernos têm fortíssima tendência a preferir a execução também específica, superando o comodismo das conversões em dinheiro, muito ao gosto dos pandectistas franceses do século XIX" (DINAMARCO, 2009, p. 514). Aludida regra da execução específica resta violada diante da doutrina da quebra eficiente, que estimula o inadimplemento nos casos em que os custos da execução se afigurem superiores aos danos acarretados à contraparte em razão do inadimplemento.

De mais a mais, o mesmo critério que, à luz da análise econômica do direito, estimula o adimplemento voluntário do negócio e a celebração de contratos, qual seja, a segurança jurídica - garantida pela possibilidade de fazer valer o acordo no judiciário -, há de ser respeitado no decorrer da inteira execução contratual, garantindo-se que haverá cumprimento integral do pactuado. Desse modo, o critério de eficiência não pode autorizar a violação do contrato.

Assim sendo, no direito brasileiro, o critério da eficiência, di per si, não determina a responsabilidade do agente ou do contratante, existindo outros valores adotados pelo legislador ou pelas partes no concreto regulamento contratual, que serão considerados pelo intérprete na imputação do dever de reparar e no cálculo da indenização.

Tal conclusão se coaduna com a ideia de que o direito não se esgota em avaliações econômicas, mas representa a concretização de várias finalidades, como a justiça e a promoção de valores existenciais, a partir da produção de normas por representantes eleitos democraticamente. Cabe, aqui, recordar a lição sempre atual do Professor Pietro Perlingieri:

A 'economic analysis', como teoria global do direito conforme a racionalidade do mercado, postula que todas as avaliações que no sistema se apresentam como fundamento dos

\footnotetext{
${ }^{35}$ Consoante dispõe o art. 1.142 do Código Civil francês: "Toda obrigação de fazer ou de não fazer se resolve em perdas e danos em caso de inexecução por parte do devedor" (tradução livre).

${ }^{36}$ Sobre o princípio da conservação negócios jurídicos, assinala Antônio Junqueira de Azevedo: "O princípio da conservação consiste, pois, em se procurar salvar tudo que é possível num negócio jurídico concreto, tanto no plano da existência, quanto da validade, quanto da eficácia. Seu fundamento prende-se à própria razão de ser do negócio jurídico; sendo este uma espécie de fato jurídico, de tipo peculiar, isto é, uma declaração de vontade (manifestação de vontade a que o ordenamento jurídico imputa os efeitos como queridos), é evidente que, para o sistema jurídico, a autonomia da vontade produzindo auto-regramentos da vontade, isto é, a declaração produzindo efeitos, representa algo de juridicamente útil. (...) O princípio da conservação, portanto, é a consequência necessária do fato de o ordenamento jurídico, ao admitir a categoria negócio jurídico, estar implicitamente reconhecendo a utilidade de cada negócio jurídico concreto" (AZEVEDO, 2008, pp. 66-67). V. tb. AMARAL, 2003, p. 544: "em caso de dúvida, deve interpretar-se o ato no sentido de produzir algum efeito, e não no sentido contrário, de não produzir nada”.
} vol. 08, nº. 04, Número Especial. Rio de Janeiro, 2015.pp. 2696-2718 
negócios, podem esgotar-se no aspecto econômico e que todas as escolhas dos sujeitos econômicos são apresentáveis em função de uma utilidade social global. Ambos os postulados parecem discutíveis. $\mathrm{O}$ jurista sabe que nem todas as avaliações do direito são traduzidas em avaliações econômicas: as soluções jurídicas são assumidas sobretudo com base no consentimento formulado em termos políticos. Com isso não se nega que possa ser útil o emprego de esquemas e critérios microeconômicos para 'escrutinar o direito' e para avaliar a congruidade de seus institutos. É, todavia, necessário ter consciência que se é verdade que a análise de custo-benefício contribui para realizar a eficiência, ela sozinha não consegue representar a especificação e a complexidade da ciência jurídica (PERLINGIERI, 2002, p. 64).

Nessa esteira, há de se compreender o contrato incompleto sob a perspectiva funcional, afastando-se sua caracterização a partir dos critérios estabelecidos pela análise econômica do direito. Do ponto de vista funcional, o contrato incompleto há de ser compreendido como negócio jurídico que emprega técnica de gestão negativa da álea normal do contrato.

A álea normal do contrato traduz os riscos econômicos previsíveis em determinado regulamento contratual concreto, que mantém relação de pertinência com a sua causa, e que consistirá em objeto de gestão pela autonomia privada, a qual irá alocar esses riscos entre os contratantes, estabelecendo como se dará a partilha dos ganhos e das perdas econômicas caso o risco se implemente.

Todos os riscos econômicos previsíveis serão objeto de gestão pelos particulares, os quais, conhecendo os possíveis riscos que poderão afetar o contrato no decorrer de sua execução, procederão à sua alocação no momento de celebração do negócio jurídico, segundo seus interesses.

Essa gestão da álea normal do contrato, de ordinário, ocorre mediante a repartição dos riscos de modo positivo entre os contratantes, de sorte que as cláusulas contratuais indicam quem é o sujeito responsável por determinado risco, que sofrerá, portanto, as perdas dele decorrentes, e quem auferirá os respectivos ganhos econômicos. Referida gestão positiva da álea normal do contrato há de ser extraída da vontade declarada dos contratantes, mediante interpretação das cláusulas contratuais.

Entretanto, em algumas hipóteses, a autonomia privada preferirá não alocar positivamente o risco econômico previsível no momento da assinatura do contrato, deixando essa decisão para momento futuro, quando e se o risco se verificar. Trata-se da denominada gestão negativa empreendida pelo contrato incompleto. Nesta hipótese, os particulares deixam lacunas no negócio, que significam a ausência de determinado elemento da relação contratual que, no entender das partes, será afetado pela oscilação da álea normal. A lacuna representa precisamente essa não tomada de decisão pelos contratantes, que remetem a distribuição dos efeitos do risco para momento futuro, por ocasião de sua verificação.

Com efeito, em determinados casos, os particulares não conseguem chegar a um acordo quanto à determinada alocação de riscos; as partes desconhecem certos aspectos mercadológicos ou fatores econômicos que poderão afetar o negócio; ou, ainda, simplesmente, não querem decidir sobre a alocação de certo risco de 
antemão. A despeito disso, desejam concluir o contrato e se vincular em caráter definitivo. Por isso, optam por firmar contrato incompleto, que permite, a um só tempo, instaurar o vínculo jurídico definitivo entre as partes e postergar a decisão quanto à alocação de determinado risco para momento futuro. Trata-se, em uma palavra, da não alocação voluntária do risco econômico (álea normal), isto é, do decidir não decidir.

Em outras palavras, sobretudo em operações econômicas complexas, marcadas pela duração no tempo e pela incerteza dos resultados, os particulares poderão concluir contrato em caráter definitivo, mas, concomitantemente, optar por não alocar ex ante certos riscos econômicos previsíveis, por entenderem que essa solução melhor atende aos seus interesses in concreto. Nesses casos, a autonomia privada celebrará contrato incompleto, o qual representa solução obrigatória, porém flexível, pois permite a abertura do regulamento contratual diante do implemento do risco, postergando, para momento futuro, a decisão quanto à alocação de riscos, segundo critérios já contratualmente definidos.

Diz-se que o regulamento contratual incompleto fornece solução obrigatória, pois estabelece o procedimento que as partes deverão seguir diante da ocorrência do risco para distribuir os ganhos e as perdas econômicas dele resultantes; e, ao mesmo tempo, traduz resposta flexível, vez que as partes irão amoldar o contrato ao novo contexto instaurado com a verificação do risco. O contrato incompleto se adapta, desse modo, à nova realidade contratual.

No contrato incompleto, portanto, as partes, deliberadamente, optam por deixar em branco determinados elementos da relação contratual, como forma de gestão negativa do risco econômico superveniente (rectius, álea normal), os quais serão determinados, em momento futuro, pela atuação de uma ou ambas as partes, de terceiro ou mediante fatores externos, segundo o procedimento contratualmente previsto para a integração da lacuna.

Os contratantes, vislumbrando a oscilação da álea normal, optam por deixar lacuna correspondente ao elemento do negócio jurídico que será afetado por essa oscilação, por entender que o regulamento contratual incompleto representa a solução que melhor atende aos seus interesses in concreto.

Quando e se o risco se concretizar, as partes distribuirão os ganhos e as perdas econômicas dele decorrentes, por meio da integração das lacunas, segundo o procedimento definido originariamente no contrato. O preenchimento da lacuna ocorrerá pela atuação de uma ou ambas as partes, de terceiro ou mediante fatores externos, consoante os critérios pactuados.

Eis a função do regulamento contratual incompleto: consentir às partes não alocar ex ante os efeitos decorrentes da variação da álea normal do contrato, remetendo essa decisão para momento futuro, como solução que melhor atende aos interesses dos particulares no caso concreto. 
A não alocação dos riscos econômicos supervenientes, mediante lacunas, a serem integradas em momento futuro, de acordo com critérios predefinidos, por uma ou ambas as partes, por terceiro ou mediante fatores externos, quando (e se) houver a verificação do risco, traduz os efeitos essenciais que integram a causa do contrato incompleto. $\mathrm{O}$ traço distintivo da causa do contrato incompleto corresponde, portanto, à gestão negativa da álea normal do contrato.

Assim sendo, com vistas a se qualificar determinado contrato como incompleto, há de se verificar se o negócio tem por função gerir negativamente a álea normal do contrato. Identificado esse traço distintivo da causa do regulamento contratual incompleto, qualifica-se o concreto negócio como contrato incompleto.

Nesse procedimento unitário de interpretação e qualificação, há de se investigar, a causa in concreto, ou seja, a função econômico-individual ou função prático-social do contrato, considerada objetivamente, e identificada no caso concreto, que exprime a racionalidade desejada pelos contratantes. A função econômicoindividual do regulamento contratual incompleto há de abranger, em definitivo, o escopo dos contratantes em gerir negativamente a álea normal do contrato.

A perspectiva funcional do contrato incompleto permite, assim, o estabelecimento de critérios para a caracterização dos negócios incompletos e de novos parâmetros interpretativos que guiarão sua execução, figurando o regulamento contratual incompleto como negócio jurídico que atende efetivamente aos interesses concretos dos particulares na gestão de riscos atinentes a complexas operações econômicas, não raro desprotegidos pela insuficiente técnica legislativa regulamentar.

De fato, os tipos contratuais tradicionais disponibilizados pelo ordenamento jurídico se mostram, no mais das vezes, insatisfatórios à proteção dos interesses da autonomia privada no exercício de suas atividades. Máxime em complexas operações econômicas que se protraem no tempo e se revestem de forte incerteza, com possibilidade de superveniência de diversos riscos econômicos.

A autonomia privada elegerá, portanto, nessas hipóteses, o contrato incompleto, com o escopo de gerir negativamente a álea normal do contrato, protegendo os seus interesses contra a oscilação da álea normal, a qual, uma vez verificada, acarretará o desequilíbrio entre as prestações, com ganhos econômicos para um dos contratantes e respectivas perdas para o outro, distribuídos ex post mediante os critérios indicados ex ante pelas partes. Por outro lado, o contrato incompleto, justamente por não conter disciplina exaustiva dos elementos da relação contratual, exige dos contratantes padrões de cooperação mais elevados relativamente aos contratos dotados de gestão positiva dos riscos, a sofrer incidência diferenciada dos princípios da boa-fé objetiva, da função social, da solidariedade social e do equilíbrio econômico dos pactos. 


\section{CONCLUSÃO}

Embora a análise econômica do direito ofereça importante contribuição ao legislador e ao intérprete, que, por vezes, irão se valer do critério de eficiência, respectivamente, na elaboração das leis e na solução dos casos concretos, a eficiência não constitui valor único do sistema jurídico, sobretudo do ordenamento personalista e solidarista vigente na legalidade constitucional, cujo valor central consiste na dignidade da pessoa humana (art. $1^{\circ}$, III, C.R.).

O sistema jurídico afigura-se unitário, dinâmico, histórico-relativo ${ }^{37}$ (HESPANHA, 2003, pp. 18-20) e aberto $^{38}$ (CANARIS, 2002, pp. 107-110; FACHIN, 2012, pp. 281-283), permeável, portanto, aos valores fundamentais da sociedade que se modificam no decorrer do tempo. A cada geração, diversos valores antagônicos e de mesma importância axiológica adquirem estatura constitucional e hão de merecer tutela nas hipóteses concretas. Na feliz síntese de Pietro Perlingieri, o direito é cultura ${ }^{39}$ (PERLINGIERI, 2005, p. 192), não se limitando à economia e ao mercado. Os padrões de eficiência propostos pela economia, desse modo, não esgotam a complexidade de valores do ordenamento, cuja unitariedade é assegurada pela Constituição da República ${ }^{40}$ (TEPEDINO, 2007, p. 313).

\footnotetext{
${ }^{37}$ Anota António Manuel Hespanha, em célebre passagem sobre a historicidade dos conceitos que, "embora muitos conceitos ou princípios jurídicos sejam muito mais modernos do que geralmente se supõe, é verdade que há outros que parecem existir, com o seu valor facial (i.e, referidos com as mesmas palavras ou como frases), desde há muito tempo. Realmente, conceitos como pessoa, liberdade, democracia, família, obrigação, contrato, propriedade, roubo, homicídio, são conhecidos como construções jurídicas desde os inícios da história do direito europeu. Contudo, se avançarmos um pouco na sua interpretação, logo veremos que, por baixo da superficie da sua continuidade terminológica, existem rupturas decisivas no seu significado semântico. $\mathrm{O}$ significado da mesma palavra, nas suas diferentes ocorrências históricas, está intimamente ligado aos diferentes contextos, sociais ou textuais, de cada ocorrência. Ou seja, o sentido é eminentemente relacional ou local. Os conceitos interagem em campos semânticos diferentemente estruturados, recebem influências e conotaçōes de outros níveis da linguagem (linguagem corrente, linguagem religiosa, etc.), são diferentemente apropriados em conjunturas sociais ou em debates ideológicos. Por detrás da continuidade aparente na superfície das palavras está escondida uma descontinuidade radical na profundidade do sentido. E esta descontinuidade semântica frustra por completo essa pretensão de uma validade intertemporal dos conceitos embebidos nas palavras, mesmo que estas permaneçam" (HESPANHA, 2003, pp. 18-20).

${ }^{38} \mathrm{Na}$ lição de Claus-Wilhelm Canaris: "Hoje, princípios novos e diferentes dos existentes ainda há poucas décadas, podem ter validade e ser constitutivos para o sistema. (...) o sistema, como unidade de sentido, compartilha de uma ordem jurídica concreta no seu modo de ser, isto é, que tal como esta, não é estático, mas dinâmico, assumindo pois a estrutura da historicidade. (...) a abertura do sistema objetivo resulta da essência do objeto da jurisprudência, designadamente da essência do Direito positivo como fenômeno colocado no processo da História e, como tal, mutável" (CANARIS, 2002, pp. 107-110). V., na mesma direção, FACHIN, 2012, pp. 281-283.

${ }^{39}$ Em suas palavras: "O ordenamento, todavia, não se exaure na complexidade da sua gênese legislativa e normativa; a complexidade do ordenamento é dada pelo impacto com o sistema sócio-cultural de atribuição, que não é aspecto factual privado de capacidade condicionante. Mas é aspecto estrutural conformativo e adequador e, portanto, realmente conteudístico do ius. Societas é cultura, e esta vive no momento de aplicação, do ordenamento criativo do caso concreto, através também da cultura dos operadores: juizes, advogados, notários, funcionários. Deste modo, a experiência enriquece a norma, plasmando-a e tornando-a eficaz" (PERLINGIERI, 2005, p. 192; tradução livre).

${ }^{40} \mathrm{Na}$ lição de Gustavo Tepedino: "Se o conceito de ordenamento pudesse se reduzir ao conjunto de normas de um mesmo nível hierárquico, poder-se-ia admiti-lo como universo técnico homogêneo e fechado em si mesmo. Sendo, ao contrário, o ordenamento jurídico composto por uma pluralidade de fontes normativas, apresenta-se necessariamente como sistema heterogêneo e aberto; e, vol. 08, nº. 04, Número Especial. Rio de Janeiro, 2015. pp. 2696-2718 
Por isso mesmo, o contrato incompleto há de ser compreendido sob a perspectiva funcional, a qual permite a concretização dos interesses das partes in concreto, e promove os valores de cooperação e solidariedade, atraindo a incidência reforçada dos princípios da boa-fé objetiva, da função social, da solidariedade social e do equilíbrio econômico dos pactos.

\title{
THE INCOMPLETE CONTRACT AND THE ECONOMIC ANALYSIS OF LAW
}

\begin{abstract}
The economic analysis of law, although gives an important contribution to the juridical institutions, puts the efficiency as the main object of the Law, ignoring others values that must be promoted, such as the dignity and the solidarity. As a consequence, the juridical institutes, specially the incomplete contract, must be considered in light of the functional perspective of the juridical facts.
\end{abstract}

Keywords: economic analysis of law; contractual law; risk; function; negative distribution of risks

\section{REFERÊNCIAS}

AGHION Philippe; BOLTON Patrick. An incomplete contracts approach to financial contracting. In: BOLTON, Patrick (Org.). The economics of contracts, Cheltenham: Edward Elgar Publishing Limited, 2008. v. 2.

AMARAL Francisco. Direito civil: introdução. Rio de Janeiro: Renovar, 2003.

AZEVEDO Antônio Junqueira de. Negócio Jurídico: existência, validade e eficácia. 4. ed. São Paulo: Saraiva, 2008.

BARROSO, Luís Roberto. Curso de direito constitucional contemporâneo. São Paulo: Saraiva, 2009.

BELLANTUONO Giuseppe. "Contratti incompleti e norme social". Rivista critica del diritto privato, Napoli: Casa Editrice Dott. Eugenio Jovene S.R.L., n. 2-3, ano 19, jun./set., 2001.

BOBBIO, Norberto. O positivismo jurídico: lições de filosofia do direito. São Paulo: Ícone, 2006.

CALABRESI, Guido. The new economic analysis of law: scholarship, sophistry or self-indulgence. London: The British Academy, 1983.

CANARIS Claus-Wilhelm. Pensamento sistemático e conceito de sistema na ciência do direito. Lisboa: Fundação Calouste Gulbenkian, 2002.

daí a sua complexidade que, só alcançará a unidade, caso seja assegurada a centralidade da Constituição, que contém a tábua de valores que caracterizam a identidade cultural da sociedade" (TEPEDINO, 2007, p. 313). 
CHEUNG Steven N. S. Transaction costs, risk aversion, and the choice of contractual arrangements. In: GEEST, Gerrit De; BERGH, Roger Van Den (org.). Comparative law and economics. Cheltenham: Edward Elgar Publishing Limited, 2004, v. 2.

Economic organization and transaction costs. In: EATWELL, John; MILGATE, Murray; NEWMAN, Peter (Org.). The new palgrave: a dictionary of economics. London: The Macmillan Press Limited, 1987, v. 2.

CLERICO Giuseppe. "Incompletezza del contrato e responsabilità delle parti". Rivista critica del diritto privato. Napoli: Casa Editrice Dott. Eugenio Jovene S.R.L., n. 3, ano 23, set. 2005.

COASE, Ronald Harry. The firm, the market and the law. Chicago: The University of Chicago Press, 1988.

DINAMARCO, Cândido. Instituições de direito processual civil. 3. ed. São Paulo: Malheiros, 2009, v. 4.

FACHIN, Luiz Edson. Direito civil: sentidos, transformações e fim. Rio de Janeiro: Renovar, 2015.

Teoria crítica do direito civil. Rio de Janeiro: Renovar, 2012.

FRIEDMAN, David. Law and economics. In: EATWELL, John; MILGATE, Murray; NEWMAN, Peter (org.). The new palgrave: a dictionary of economics. London: The Macmillan Press Limited, 1987, v. 3.

HART, Oliver. Incomplete contract. In: EATWELL, John; MILGATE, Murray; NEWMAN, Peter (org.). The new palgrave: a dictionary of economics. London: The Macmillan Press Limited, 1987 v. 2.

HESPANHA, António Manuel. Cultura jurídica europeia. Mira-Sintra: Mem Martins: Publicações EuropaAmérica, 2003.

FRANZONI, Luigi Alberto. Introduzione all'economia del diritto. Bologna: Mulino, 2003.

MATTEI, Ugo et al. Il mercato delle regole: analisi economica del diritto civile. Bologna: Società editrice il Mulino, 1999.

MORAES, Maria Celina Bodin de. Na medida da pessoa humana: estudos de direito civil-constitucional. Rio de Janeiro: Renovar, 2010.

MÜLLER, Christian; TIETZEL, Manfred. Property rights and their partitioning. In: BACKHAUS, Jürgen G. (org.). The Elgar companion to law and economics. Cheltenham: Edward Elgar Publishing Limited, 1999.

PARISI, Francesco. Coase theorem and transaction cost economics in law. In: The Elgar companion to law and economics, Cheltenham: Edward Elgar Publishing Limited, 1999.

PERLINGIERI, Pietro. “Complessità e unitarietà dell'ordinamento giuridico vigente". Rassegna di diritto civile. Napoli: Edizioni Scientifiche Italiane, 2005, v. 1.

O direito civil na legalidade constitucional. Trad. Maria Cristina de Cicco. Rio de Janeiro: Renovar, 2008. Perfis de direito civil: introdução ao direito civil constitucional. 2. ed. Rio de Janeiro: Renovar, 2002.

POSNER, Richard A. Economic analysis of law, Boston: Little, Brown and Company, 1972.

Economic analysis of law. 7. ed. New York: Aspen Publishers, 2007.

SANTOS, J. M. Carvalho. Código civil brasileiro interpretado. v. 14. 8. ed. Rio de Janeiro: Freitas Bastos, 1964. 
SARMENTO, Daniel. O neoconstitucionalismo no Brasil: riscos e possibilidades. In: SARMENTO, Daniel. Por um constitucionalismo inclusivo: história constitucional brasileira, teoria da constituição e direitos fundamentais. Rio de Janeiro: Lumen Juris, 2010.

STEIGER, Otto. Ex ante and ex post. In: EATWELL, John; MILGATE, Murray; NEWMAN, Peter (org.). The new palgrave: a dictionary of economics. London: The Macmillan Press Limited, 1987, v. 2.

TEPEDINO, Gustavo. "Liberdades, tecnologia e teoria da interpretação". Revista Forense, São Paulo: Editora Forense. v. 419, 2014.

Normas constitucionais e direito civil na construção unitária do ordenamento. In: SOUZA NETO, Cláudio Pereira de; SARMENTO, Daniel (coord.). A constitucionalização do direito. Rio de Janeiro: Editora Lumen Juris, 2007.

WITTMAN, Donald. Economic foundations of law and organization. Cambridge: Cambridge University Press, 2006.

Trabalho enviado em 19 de janeiro de 2016.

Aceito em 29 de janeiro de 2016. 